\title{
Membrane Stabilizing and Preliminary Hypoglycemic Activities of Picrasma javanica
}

\author{
Tasnuva Sharmin, Farhana Islam, Md. Al Amin Sikder, Shaila Kabir, \\ Mohammad Rashedul Haque and Mohammad A. Rashid
}

\author{
Phytochemical Research Laboratory, Department of Pharmaceutical Chemistry, Faculty of Pharmacy \\ University of Dhaka, Dhaka-1000, Bangladesh
}

\begin{abstract}
The methanol extract of leaves of Picrasma javanica Blume and its $n$-hexane, carbon tetrachloride, chloroform and aqueous soluble partitionates were evaluated for membrane stabilizing and preliminary hypoglycemic activities. In hypotonic solution and heat-induced conditions, the crude methanol extract inhibited $65.30 \pm 0.52 \%$ and $36.79 \pm 0.38 \%$ haemolysis of RBC as compared to $72.79 \%$ and $42.12 \%$ produced by standard drug, acetyl salicylic acid, respectively $(0.10 \mathrm{mg} / \mathrm{ml})$. The crude extract also showed blood sugar lowering efficacy at 200 and $400 \mathrm{mg} / \mathrm{kg}$ body weight, with $48.63 \%$ reduction of blood sugar level at $400 \mathrm{mg} / \mathrm{kg}$ body weight while the standard drug, Glibenclamide (10 mg/kg body weight) demonstrated $53.7 \%$ reduction of blood sugar level at $3^{\text {rd }}$ hour of administration.
\end{abstract}

Key words: Picrasma javanica Blume, membrane stabilization, hypoglycemic, Glibenclamide.

\section{Introduction}

Picrasma javanica Blume (Synonyms: P. nepalensis A.W. Bennet and P. philippinensis Elmer; Bengali name: Nilghanta) belonging to the family Simarubaceae, grows in Java Islands at 150-1400 m altitude. The plant occurs from the North-Eastern India throughout South East Asia to the Solomon's islands. In Bangladesh, it can be found in forests of Chittagong, Chittagong Hill Tracts and Cox's Bazar. Traditionally, the bark of the plant is used as a febrifuge where it is known to be a substitute for quinine (Heyne, 1987). Previous studies with $P$. javanica revealed anti-malarial and anti-cancer activities (Saiin et al., 2003).

As a part of our continuing investigation of medicinal plants of Bangladesh (Kaisar et al., 2011; Sharmin et al., 2012), the crude methanol extract of leaves of $P$. javanica as well as its organic and aqueous soluble fractions were studied for membrane stabilizing and hypoglycemic activities for the first time in Bangladesh.

\section{Materials and Methods}

Collection of plant materials and extraction: The leaves of $P$. javanica were collected in mid 2011 from Khagrachori and a voucher specimen (DUSH-10771) has been deposited in Salar Khan Herbarium, Department of Botany, University of Dhaka.
Extraction and fractionation: Collected plant materials were cleaned, chopped, dried to facilitate grinding. The powdered material (500 gm) was soaked in 2.0 liter of methanol at room temperature for 7 days. The extract was filtered through fresh cotton bed and finally with Whatman filter paper number 1 and concentrated with a rotary evaporator at reduced temperature $\left(40-50{ }^{\circ} \mathrm{C}\right)$ and pressure. An aliquot (5 gm) of the concentrated methanol extract was fractionated by modified Kupchan (VanWagenen et al., 1993) partitioning protocol and the resultant fractions were evaporated to dryness with rotary evaporator to yield hexane (HXSF, $1500 \mathrm{mg}$ ), carbon tetrachloride (CTCSF, $950 \mathrm{mg}$ ), chloroform (CSF, 800 $\mathrm{mg}$ ) and aqueous (AQSF, $500 \mathrm{mg}$ ) soluble materials. The residues were then stored in a refrigerator until further use.

Membrane stabilizing activity: The membrane stabilizing activity of the extractives was assessed by using hypotonic solution- and heat-induced haemolysis of human erythrocyte by the method developed by Omale and Okafor (2008).

Hypotonic solution-induced haemolysis: The test sample consisted of stock erythrocyte (RBC) suspension $(0.50 \mathrm{ml})$ mixed with $4.5 \mathrm{ml}$ of hypotonic solution (50 $\mathrm{mM} \mathrm{NaCl}$ ) in $10 \mathrm{mM}$ sodium phosphate buffered saline (pH 7.4) containing either the extract $(2.0 \mathrm{mg} / \mathrm{ml})$ or acetyl salicylic acid $(0.1 \mathrm{mg} / \mathrm{ml})$. The control sample consisted of $0.5 \mathrm{ml}$ of RBC suspension mixed with hypotonic buffered

Correspondence to: Mohammad A. Rashid; Tel.: 880-2-9661900, Extn.- 8137, 8131; Fax: 880-2-8615583; E-mail: rashidma@du.ac.bd 
saline alone. The mixture was incubated for 10 minutes at room temperature, centrifuged for 10 minutes at $3000 \mathrm{~g}$ and the absorbance of the supernatant was measured at $540 \mathrm{~nm}$. The percentage inhibition of haemolysis was calculated using the following equation-

$\%$ Inhibition of haemolysis $=100 \times\left(\mathrm{OD}_{1}-\mathrm{OD}_{2} / \mathrm{OD}_{1}\right)$, where, $\mathrm{OD}_{1}=$ optical density of hypotonic buffered saline solution alone (control) and $\mathrm{OD}_{2}=$ optical density of test sample in hypotonic solution.

Heat induced haemolysis: Isotonic buffer containing aliquot (5 ml) of the different extractives was put into two duplicate sets of centrifuge tubes. The vehicle, in the same amount, was added to another tube as control. Erythrocyte suspension $(30 \mu \mathrm{l})$ was added to each tube and mixed gently by inversion. One set of the tubes was incubated at $54{ }^{\circ} \mathrm{C}$ for 20 minute in a water bath, while the other set was maintained at $0^{\circ}-5^{\circ} \mathrm{C}$ in an ice bath. The reaction mixture was centrifuged for 3 minute at $1300 \mathrm{~g}$ and the absorbance of the supernatant was measured at 540nm. Then the percentage inhibition or acceleration of haemolysis was calculated according to the following equation:

$\%$ Inhibition of haemolysis $=100 \times\left[1-\left(\mathrm{OD}_{2}-\mathrm{OD}_{1} /\right.\right.$ $\left.\left.\mathrm{OD}_{3}-\mathrm{OD}_{1}\right)\right]$

where, $\mathrm{OD}_{1}=$ optical density of unheated test sample, $\mathrm{OD}_{2}=$ optical density of heated test sample and $\mathrm{OD}_{3}=$ optical density of heated control sample

Hypoglycemic activity assay: Here the lowering of blood glucose level of the experimental animals was measured by tail tipping method (Durschlag et al., 1996) on Swiss albino mice, aged 4-5 weeks and weighing about 20-25 g. The mice were procured from the Animal Resource Branch of the International Centre for Diarrhoeal Diseases and Research, Bangladesh (ICDDR,B). Before initiating the experiment, the mice were acclimatized for few days under standard environmental conditions (12 hours dark/12 hours light cycle, temperature $20-22^{\circ} \mathrm{C}$, relative humidity $40-60 \%$ ) and fed with ICDDR,B formulated rodent food and water.

Chemicals and drugs: Glibenclamide (Daonil) from Sanofi-Aventis was used as standard drug. Tween-80 (BDH Chemicals Ltd.) and Dimethyl sulphoxide (DMSO, Merck Chemicals Ltd., Germany) were used as solvent and suspending agent, respectively. Sterile normal saline solution $(0.9 \% \mathrm{NaCl})$ from Beximco Infusion Ltd.
(Bangladesh) was used as vehicle for standard and test samples.

Preparation of the test materials, standard and control: In order to administer the crude methanol extract at 200 and $400 \mathrm{mg} / \mathrm{kg}$ body weight, the exact amount of extract was weighed and triturated in unidirectional way by adding small amount of Tween-80. After proper mixing of extract and the suspending agent, normal saline was slowly added. The final volume of the suspension was made $3.0 \mathrm{ml}$. To stabilize the suspension, it was stirred well with a vortex mixture.

For the preparation of standard (Glibenclamide) at the dose of $10 \mathrm{mg} / \mathrm{kg}$ body weight, $10 \mathrm{mg}$ tablet was dissolved into $3.0 \mathrm{ml}$ normal saline $(0.9 \% \mathrm{NaCl})$. For preparing control, $2 \mathrm{ml}$ Tween-80 (1\% solution in water) were mixed properly in $3 \mathrm{ml}$ normal saline to make the volume $5 \mathrm{ml}$.

Experimental design: The experimental animals were randomly divided into four groups (I to V) consisting of five mice in each group. Test samples at 200 and 400 $\mathrm{mg} / \mathrm{kg}$ body weight were used to evaluate the hypoglycemic activity. Standard glibenclamide was used at a dose of $10 \mathrm{mg} / \mathrm{kg}$ body weight. Each mouse was weighed properly and the doses were adjusted accordingly (Table 1).

Table 1. Test materials used in the evaluation of hypoglycemic effect of the crude methanol extract of $P$. javanica.

\begin{tabular}{lc}
\hline Group & Dose $(\mathrm{mg} / \mathrm{kg})$ \\
\hline I (Control group) & $0.1 \mathrm{ml} / 10 \mathrm{~g}$ of body wt \\
II (Standard group) & 10 \\
III (Test sample) & 400 \\
IV (Test sample) & 200 \\
\hline
\end{tabular}

Experimental procedure: In the evaluation of the hypoglycemic effect of the crude methanol extract of $P$. javanica, the blood glucose level of the experimental animals was measured at zero hour using a glucometer (Bioland G-423 S). Then the control, standard and methanolic crude extract (200 and $400 \mathrm{mg} / \mathrm{kg}$ body weight) were administered orally to the experimental animals with the help of feeding needle. At $1^{\text {st }}, 2^{\text {nd }}$ and $3^{\text {rd }}$ hours after administration, the blood glucose level of the experimental animals were measured to observe the hypoglycemic effect of the test samples relative to control and standard groups. 
Statistical analysis: Three replicates of each sample were used for statistical analysis and the values are reported as mean \pm SD. Experimental groups were compared with control group by t- test.

\section{Results and Discussion}

The crude methanol extract of $P$. javanica as well as different Kupchan partitionates derived from it were subjected to assay for membrane stabilizing and hypoglycemic activities.

In membrane stabilizing activity assay, all the extractives of $P$. javanica significantly protected the lysis of human erythrocyte membrane induced by hypotonic solution and heat, as compared to standard acetyl salicylic acid. In hypotonic solution and heat induced conditions, the methanol extract inhibited $65.30 \pm 0.52 \%$ and $36.79 \pm 0.38 \%$ haemolysis of RBC as compared to $72.79 \%$ and $42.12 \%$ inhibited by acetyl salicylic acid (0.10 $\mathrm{mg} / \mathrm{ml}$ ), respectively. The $n$-hexane soluble fraction demonstrated $58.98 \pm 0.61 \%$ and $31.94 \pm 0.57 \%$ inhibition of hypotonic solution- and heat-induced haemolysis of RBCs, respectively (Table 2).

Table 2. Percentage inhibition of hypotonic solution and heat induced haemolysis of erythrocyte membrane by $P$. javanica extractives $(2 \mathrm{mg} / \mathrm{ml})$ and ASA $(0.10 \mathrm{mg} / \mathrm{ml})$.

\begin{tabular}{ccc}
\hline Samples/ & \multicolumn{2}{c}{ \% inhibition of Haemolysis } \\
\cline { 2 - 3 } Standard & $\begin{array}{c}\text { Hypnotic solution } \\
\text { induced }\end{array}$ & Heat induced \\
\hline ME & $65.30 \pm 0.52$ & $36.79 \pm 0.38$ \\
HXSF & $58.98 \pm 0.61$ & $31.94 \pm 0.57$ \\
CTCSF & $48.29 \pm 0.06$ & $29.39 \pm 0.64$ \\
CSF & $20.71 \pm 0.34$ & $13.53 \pm 0.42$ \\
AQSF & $47.62 \pm 0.19$ & $24.88 \pm 0.33$ \\
ASA & $72.79 \pm 0.47$ & $42.12 \pm 0.23$ \\
\hline
\end{tabular}

ME = Methanolic crude extract; HXSF = Hexane soluble fraction; $\mathrm{CTCSF}=$ Carbon tetrachloride soluble fraction; $\mathrm{CSF}=$ Chloroform soluble fraction; AQSF = Aqueous soluble fraction; ASA= Acetyl salicylic acid

The crude methanol extract of $P$. javanica revealed hypoglycemic activity at 200 and $400 \mathrm{mg} / \mathrm{kg}$ body weight. At $3^{\text {rd }}$ hour of administration, the crude methanol extract displayed $48.63 \%$ and $35.56 \%$ reduction of blood sugar level at 400 and $200 \mathrm{mg} / \mathrm{kg}$ of body weight, respectively (Tables 3 and 4).
Table 3. Effect of crude extract of $P$. javanica on blood glucose level of Swiss albino mice.

\begin{tabular}{ccccc}
\hline \multirow{2}{*}{ Groups } & \multicolumn{4}{c}{ Blood glucose level (mmole/L) } \\
\cline { 2 - 5 } & $0 \mathrm{~min}$ & $1 \mathrm{hr}$ & $2 \mathrm{hr}$ & $3 \mathrm{hr}$ \\
\hline \multirow{2}{*}{ I } & $5.98 \pm$ & $5.72 \pm$ & $5.70 \pm$ & $5.63 \pm$ \\
& 0.112 & 0.491 & 0.344 & 0.559 \\
\multirow{2}{*}{ II } & $5.96 \pm$ & $2.00 \pm$ & $2.54 \pm$ & $2.76 \pm$ \\
& 0.308 & $0.071^{*}$ & $0.133^{*}$ & $0.163^{*}$ \\
III & $5.86 \pm$ & $3.12 \pm$ & $3.03 \pm$ & $3.01 \pm$ \\
& 0.732 & $0.453^{*}$ & $0.920^{*}$ & $0.023^{*}$ \\
IV & $5.40 \pm$ & $3.82 \pm$ & $3.62 \pm$ & $3.48 \pm$ \\
& 0.534 & $0.334^{*}$ & $0.015^{*}$ & $0.492^{*}$ \\
\hline
\end{tabular}

Experimental (III and IV) and standard (II) groups were compared with control group (I) by t- tests $(* \mathrm{P}<0.05)$.

Table 4. Percentage of blood glucose reduction in Swiss albino mice by methanol extract of $P$. javanica.

\begin{tabular}{cccc}
\hline \multirow{2}{*}{ Groups } & \multicolumn{3}{c}{ \% of blood glucose level reduction } \\
\cline { 2 - 4 } & 1 hour & 2 hour & 3 hour \\
\hline I & 4.35 & 4.68 & 5.85 \\
II & 66.4 & 57.4 & 53.7 \\
III & 46.76 & 48.29 & 48.63 \\
IV & 29.26 & 32.96 & 35.56 \\
\hline
\end{tabular}

It is clearly evident from the above findings that $P$. javanica has significant membrane stabilizing activity. The plant also showed moderate hypoglycemic potential. Therefore, it is a good candidate for further systematic chemical and biological studies to isolate the active principles.

\section{Acknowledgement}

One of us (TS) acknowledges the Ministry of Science and Technology (MOST), Government of the People's Republic of Bangladesh for a fellowship to carry out the work.

\section{References}

Durschlag, M., Wurbel, H., Stauffacher, M. and Von Holst, D. 1996. Repeated blood collection in the laboratory mouse by tail incision-modification of an old technique. Physiol. Behav. 60, 1565-1568.

Kaisar, M.A., Rahman, M.S., Rahman, M.Z., Hasan, C.M. and Rashid, M.A. 2011. A review on phytochemicals from some medicinal plants of Bangladesh. J. Phar. Nutri. Sci. 1, 8795.

Heyne, K. 1987. In: Tumbuhan Berguna Indonesia II. Badan Litbang Kehutanan, Jakarta, vol. 4, pp. 493-494. 
Omale, J. and Okafor, P.N. 2008. Comparative antioxidant capacity, membrane stabilization, polyphenol composition and cytotoxicity of the leaf and stem of Cissus multistriata. Afr. J. Biotechnol. 7, 3129-3133.

Saiin, C., Rattanajak, R., Kamchonwongpaisan, S., Ingkaninan, K., Sukontason, K., Baramee, A. and Sirithunyalug, B. 2003. Isolation and in vitro antimalarial activity of hexane extract from Thai Picrasma javanica B1 stembark. Southeast Asian J. Trop. Med. Publ.Health. 34, 51- 55.
Sharmin, T., Islam, F., Kaisar, M.A., Uddin, M.G. and Rashid, M.A. 2012. Antioxidant, Thrombolytic and cytotoxic activities of Picrasma javanica. Dhaka Univ. J. Pharm. Sci. 11, 71-74.

Vanwagenen, B.C., Larsen, R., Cardellina, J.H., Randazzo, D., Lidert, Z.C. and Swithenbank, C. 1993. Ulosantoin, a potent insecticide from the sponge Ulosa ruetzleri. J. Org. Chem. 58, 335-337. 